DOI: 10.18468/rbli.2020v3n1.p160-176

\title{
Empréstimos do Português para a Língua Geral no Século XVIII
}

\author{
Portuguese Loanwords for the Língua Geral in The XVIII Century
}

\author{
Bárbara Heliodora Lemos de Pinheiro Santos \\ Universidade de Brasília (UnB)
}

\begin{abstract}
Resumo. O contato entre o Português e a Língua Geral (LG) tem sido uma realidade na região amazônica desde que os primeiros colonos chegaram a esse território em 1616. Desde o primeiro contato, a LG começou a receber empréstimos do Português, assim como o Português também passou a receber empréstimos da LG. No entanto, é a partir do que século XVIII que o número de empréstimos lexicais da Língua Portuguesa na LG começa a ficar mais evidente, à medida que o bilinguismo entre LG e Português começa, do mesmo modo, a desenvolver-se e a avançar. Ao analisar a "Grammatica da lingua geral do Brazil. Com hum diccionario dos vocábulos mais usuaes para a intelligencia da dita língua gramática", o "Dicionario da lingua geral do Brasil que se falla em todas as villas, lugares e aldeas deste vastissimo Estado" e o "Dicionário da Língua Brasílica", documentos de autoria anônima que registram a LG do século XVIII, este artigo tem, como finalidade, discutir e analisar as estratégias fonológicas que têm sido utilizadas para que palavras do Português façam parte do léxico da LG nesse mesmo século.
\end{abstract}

Palavras chave: Contato; Língua Geral; Empréstimo; Estratégias fonológicas.

Abstract. Contact between Portuguese and Língua Geral (LG) has been a reality in the Amazon region since the first settlers arrived in this territory in 1616 . From the first contact, LG began to receive loanwords from the Portuguese, just as the Portuguese also began to receive loanwords from LG. However, it is from the 18th century onwards that the number of lexical loans from the Portuguese language at LG begins to become more evident as bilingualism between LG and Portuguese begins to develop and advance. In analyzing the "Grammatica da lingua geral do Brazil. Com hum diccionario dos vocábulos mais usuaes para a intelligencia da dita língua gramática", the "Dicionario da lingua geral do Brasil que se falla em todas as villas, lugares e aldeas deste vastissimo Estado" and the "Dicionário da Língua Brasílica", documents of anonymous authorship that register the LG of the 18th century, this article aims to discuss and analyze the phonological strategies that have been used to make words of Portuguese part of the LG lexicon in that same century.

Keywords: Contact; Língua Geral; Loanword; Phonological strategies.

\section{Introdução}

Ao chegarem no Pará em 1616, conforme Bessa Freire (2004, p. 51), os colonos portugueses defrontaram-se com centenas de línguas indígenas na Amazônia, dentre elas, o Tupinambá ${ }^{1}$, falado na costa do Salgado até a boca do rio Tocantins. Nesse contexto, a interação entre colonizadores e indígenas, a troca de informações e o processo para disciplinar a força de trabalho por meio da catequese

1. Conforme Rodrigues (1994, p. 100), o nome Tupinambá aparece tardiamente, no século XVIII, já com a intenção de distinguir a língua dos índios Tupinambá da então língua corrente da população mestiça. 
só poderiam ser viabilizados, ainda de acordo com Bessa Freire (2004, p. 46), com a superação da diversidade linguística, com o desenvolvimento de uma língua de contato e com a criação de uma nova comunidade de fala.

O Português, no entanto, não poderia ser essa língua franca, tendo em vista que, no Grão-Pará², a ocupação lusa ainda não estava consolidada e os diferentes povos indígenas ainda estavam em total posse de seus territórios. Assim, a língua do colonizador ficou restrita à função de comunicação com a metrópole, enquanto as relações sociais na Amazônia, durante todo o período colonial, segundo Bessa Freire (2004, p. 50), tiveram como base uma língua indígena, o Tupinambá, situação que perdurou até mesmo após a Independência do Brasil. De acordo com Rodrigues (1994, p. 99 e 100), essa língua, de base Tupi-Guarani, recebeu diversos nomes, entre os quais, Língua mais usada na Costa do Brasil; Língua da terra (desta terra, do Brasil); Língua do mar (língua falada na costa, junto ao mar). O nome firmado, entretanto, foi o de Língua Brasílica.

De acordo com Bessa Freire (2004, p. 51), o Tupinambá acabou, então, por exercer a função inicial de língua de comunicação entre os portugueses e os diferentes povos indígenas da região. A partir disso, Rodrigues (1996, p. 10) afirma que surgiu uma população mestiça de pais europeus e de mães indígenas, cuja língua dos filhos é oTupinambá. Nesse processo histórico de constituição e de expansão, o Tupinambá passa a ser conhecido, a partir da segunda metade do século XVII, como Língua Geral (doravante, LG)3 a qual foi progressivamente reajustando-se e diferenciando-se do Tupinambá falado por indígenas que sobreviveram até meados do século XVIII (RODRIGUES, 1996, p.10). Durante os séculos XVII e XVIII, a LG espalhou-se pela região amazônica, onde passou a funcionar como língua interétnica (BESSA FREIRE, 2004), isto é, essa língua passou a exercer a função de comunicação entre falantes de diferentes etnias.

Como consequência desse longo período de contato linguístico, várias palavras do Português foram incorporadas a léxico da LG. Nesse sentido, este artigo tem como propósito identificar quais foram os mecanismos fonológicos utilizados pelos falantes de LG no séculoXVIII para receberem os empréstimos advindos do Português. Esses mecanismos serão divididos, neste trabalho, em adaptação segmental, adaptação silábica e adaptação acentual.

Um número significativo de trabalhos apresenta e discute empréstimos linguísticos de línguas indígenas na Língua Portuguesa (cf. NOLL, 2015; DIETRICH \& NOLL, 2015). Mais raros, entretanto, são os trabalhos que apontam os empréstimos do Português em alguma língua indígena. Edelweiss (1969), por exemplo, fez o levantamento dos empréstimos do Português na LG a partir de dicionários e de vocabulários do século XVIII. Todavia, o autor conteve-se apenas ao levantamento desses vocábulos, sem realizar análise fonológica. Monserrat (2003), por outro lado, realiza uma análise fonológica da LG do século XVIII a fim de reconstruir o estágio de desenvolvimento da LG falada nesse período. Porém, a autora apresenta poucos exemplos de empréstimos. Este trabalho diferencia-se dos trabalhos citados anteriormente, pois faz o levantamento dos empréstimos do Português que entraram no léxico da LG

2. O estado do Maranhão e Grão-Pará era uma das duas colônias portuguesas do continente e hoje sua extensão territorial abrange os estados do Maranhão, do Piauí, do Pará, do Amazonas e de Roraima.

3. Rodrigues (1986, p. 102) propõe uma distinção entre Língua Geral Paulista (que se desenvolveu, a partir do Tupiniquim, no sul da Colônia) e Língua Geral Amazônica (que se desenvolveu, a partir do Tupinambá, no norte da Colônia). Apesar dessa proposta, este trabalho utilizará, simplesmente, o termo Língua Geral para se referir à língua que se desenvolveu a partir do Tupinambá no norte do território brasileiro. 
do século XVIII, além de discutir e analisar fonologicamente quais são as estratégias que estão sendo utilizadas para que a LG receba as novas palavras vindas do Português a partir do contato linguístico.

Para o levantamento dos dados analisados aqui, foram utilizados três documentos produzidos no século XVIII. Esses documentos, listados no quadro 1 abaixo, tratam-se de uma gramática e de dois dicionários.

Quadro 1: Documentos usados para o levantamento de dados

\begin{tabular}{|l|l|l|}
\hline TíTULO & BIBLIOTECA & REFERÊNCIA \\
\hline $\begin{array}{l}\text { Grammatica da lingua geral do } \\
\text { Brazil. Com hum diccionario dos } \\
\text { vocábulos mais usuaes para a } \\
\text { intelligencia da dita língua }\end{array}$ & Universidade de Coimbra & códice 69 (inédito) \\
\hline $\begin{array}{l}\text { Dicionario da lingua geral do Brasil } \\
\text { que se falla em todas as villas, lugares } \\
\text { e aldeas deste vastissimo Estado. } \\
\text { Escrito na cidade do Pará, anno 1771) }\end{array}$ & Universidade de Coimbra & ms. 81 (inédito) \\
\hline Dicionário da Língua Brasílica & Universidade de Coimbra & códice 94 \\
\hline
\end{tabular}

É possível que os documentos aqui utilizados para o levantamento de dados não sejam linguisticamente homogêneos. Isso pode ser observado pelo fato de haver palavras iguais registradas com grafias diferentes, por exemplo. Nesse sentido, propõe-se olhar para essa documentação como uma síntese das variedades da LG do século XVIII, a qual pode representar o registro de mais de um período do idioma. Devido à grande possibilidade de a documentação não ser homogênea, não se espera, portanto, que o conjunto de regras aqui discutidas explique uniformemente todo o conjunto de empréstimos que possa ser encontrado. O que se propõe neste artigo, então, é a discussão dos empréstimos registrados nos documentos citados e, sempre que viável, uma proposta de generalização.

Para os devidos fins, este artigo foi organizado da seguinte forma: na seção 2, os sistemas fonológicos do Português e da LG do século XVIII foram brevemente descritos; em seguida, foram discutidas as diferenças entre esses dois sistemas. Essa descrição fez-se necessária para que se compreendam os mecanismos usados pela LG para lidar com os verbos e nomes emprestados do Português (discutidos nas seções 3 e 4 respectivamente). Por fim, na seção 5, apresentam-se as principais considerações deste artigo.

\section{Sistemas fonológicos do Português e da LG no século XVIII}

Os sistemas fonológicos da LG e do Português, no século XVIII, diferenciam-se de distintas maneiras. Para que tais distinções sejam discutas, são apresentados primeiramente, os sistemas consonantais das duas línguas no século XVIII. Em seguida, as estruturas silábicas e o padrão acentual do Português e da LG são comparadas.

Para a discussão acerca da fonologia da LG do século XVIII, utilizou-se a análise feita por Monserrat (2003). Por sua vez, a discussão sobre a fonologia do Português do século XVIII é baseada em Câmara Jr. (1976), Teyssier (1990) e Silva (1991). Os dois sistemas consonantais são apresentados nas tabelas 1 e 2 respectivamente. 
Tabela 1: Sistema consonantal da LG do século XVIII

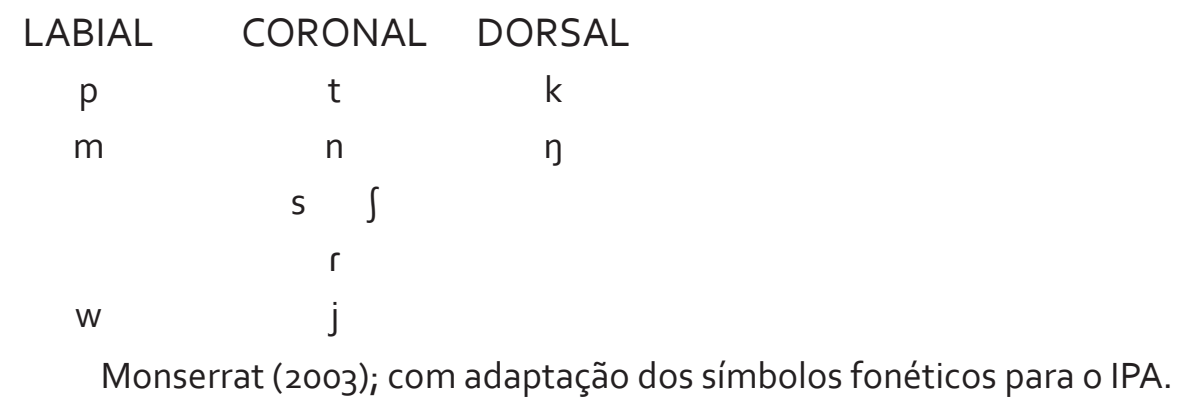

Tabela 2: Sistema consonantal do Português do século XVIII

\begin{tabular}{|c|c|c|c|}
\hline \multirow{2}{*}{ LABIAL } & \multicolumn{2}{|c|}{ CORONAL } & \multirow{2}{*}{ DORSAL } \\
\hline & \multicolumn{2}{|c|}{ [+anterior] [-anterior] } & \\
\hline $\mathrm{p}$ & \multicolumn{2}{|c|}{$\mathrm{t}$} & k \\
\hline$b$ & \multicolumn{2}{|c|}{$d$} & $\mathrm{~g}$ \\
\hline $\mathrm{m}$ & $\mathrm{n}$ & $\mathrm{n}$ & \\
\hline$f$ & s & $\int$ & \\
\hline \multirow[t]{2}{*}{$v$} & $\mathrm{z}$ & 3 & \\
\hline & I & $\Lambda$ & \\
\hline
\end{tabular}

Baseado em Câmara Jr. (1976), Teyssier (1990), Silva (1991)

Como sabemos, o sistema fonológico do Português estabelece uma tripla oposição entre obstruintes vozeadas /b, d, g/, desvozeadas /p, t, k/ e nasais /m, n, n/. Entre as fricativas, o traço [ \pm voz] permite a distinção entre uma série de fricativas vozeadas $/ v, z, 3 /$ e desvozeadas /f, s, $\int /$. Por sua vez, o sistema fonológico da LG estabelece uma dupla oposição entre as obstruintes: surdas /p, t, k/ e nasais /m, n, $\mathrm{\eta} /$. $\mathrm{Na}$ ausência de uma série de oclusivas vozeadas, a série de nasais realiza-se como nasais plenas [ $m, n$, $\eta]$ ou como segmentos pré-nasalizados $\left[{ }^{m} b,{ }^{n} d,{ }^{n} g\right]$. No que concerne às fricativas, distinguem-se duas fricativas desvozeadas /s/ e / /. Cabe notar, como observou Monserrat (2003, p. 193), a consoante palatal fricativa / / / era, no Tupinambá, alofone do fonema /s/. Ainda segundo essa autora, esse segmento emerge como fonema na LG do século XVIII.

A LG tem uma líquida, o tepe /r/, ao passo que o Português apresenta o tepe /r/ e as aproximantes laterais /// e / $/$. Em Português, há também a distinção entre o tepe /r/ e a vibrante múltipla /r/ em posição intervocálica, como em caro ['ka.rv] e carro ['ka.ro] respectivamente.

Mais uma diferença a ser salientada entre os dois sistemas consonantaisé que a LG possuiuma consoante nasal dorsal / $\mathrm{h} /$, enquanto o Português possui uma consoante nasal palatal $/ \mathrm{n} /$. Por fim, Monserrat (2003) integra os glides / w/ e /j/ como fonemas em sua proposta de inventário. De acordo com a autora, o glide /w/ possui diversas representações gráficas, sendo algumas delas $\langle\mathrm{b}\rangle$ e $\langle\mathrm{v}\rangle$. Para a autora, /w/ aparece grafado como $<b>$ em posição de ataque silábico em um ambiente de vogais orais. Sobre a ocorrência como $\langle v\rangle$, a autora não faz nem uma consideração. Este trabalho, diferentemente do que propõe Monserrat (2003), segue a análise de Cruz (2011), que interpreta a fricativa bilabial sonora 
$[\beta]^{4}$ como um alofone do fonema $/ \mathrm{m} / \mathrm{da} L \mathrm{LG}$. A proximidade do som de $[\beta]$ com a fricativa labiodental vozeada [v] e com a oclusiva labial vozeada [b] causaria, portanto, a variação na grafia de palavras com $<v>$ e $<b>$ do Português na LG. No Português, os glides [j] e [w] não são fonemas.

As duas línguas também diferem-se substancialmente em relação ao sistema vocálico. O Português possui sete vogais orais em sílabas tônicas primárias /a $\varepsilon$ e i ว o u/ de acordo com Câmara Jr. (1976), Teyssier (1990) e Silva (1991), com cinco vogais nasais alofônicas /ã ẽ ĩ õ ũ/, as quais ocorrem diante de consoantes nasais, conforme a análise de Câmara Jr. (1976). Por outro lado, o sistema de vogais da LG é caracterizado por seis vogais orais /a e i i o u/e cinco vogais nasais /ã ẽ ĩ ₹̃o/, conforme Monserrat (2003, p. 188). As vogais orais /e/ e /o/ possuem alofones, que são realizados como [E] e [J] em posição tônica e como [e] e [o] em posição átona. Esse fenômeno é muito comum nas línguas Tupi-Guarani, como no Kamaiurá (SEKI, 2000, p. 415), no Mbyá-Guarani (MARTINS, 2003, p.169), no Avá-Canoeiro

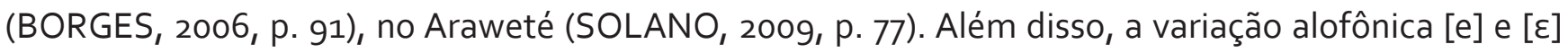
também ocorre em Nheengatu, variedade moderna da LG (CRUZ, 2011, p. 58).

Em relação à estrutura silábica, a LG é mais restritiva que o Português. O Português permite estruturas silábicas mais complexas: $(C)(C) \vee(C)$ (cruz, carta, almoço). Na posição de coda, o Português permite apenas sons soantes (glides, líquidas e nasais) e $/ \mathrm{s} /$. O segundo elemento do ataque ramificado deve ser ocupado por um glide ou por uma líquida. Em contrapartida, a estrutura silábica da LG não permite ataque de sílaba ramificado. No Tupinambá, Monserrat (2003, p. 193) observa que, na posição de coda em final de palavras, era possível ocorrer os glides e as consoantes $[\beta, k, m, n, \eta, r]$. No entanto, ainda segundo a autora, na LG do século XVIII, essa ocorrência tende a ser reduzida, aparecendo, esporadicamente, apenas as consoantes $[k, r]$ e, ainda assim, em flutuação com as formas seguidas por vogais, pelos glides $[j, w]$ e pela nasal velar $[\eta]$.

Por fim, em relação ao padrão acentual, Wetzels (1977) afirma que, em Português, a maior parte dos não-verbos seguem o padrão acentual troqueu moraico (escola; fogo; janela). Isso significa que a maioria das palavras dessa língua possui a tonicidade na penúltima sílaba. A LG, por outro lado, apresenta um padrão acentual iâmbico no século XVIII, isto é, os pés métricos são formados da direita para a esquerda com proeminência à direita (kunhã 'mulher'; imyrá 'árvore'), como ocorre na maioria das línguas da família Tupi-Guarani ( WETZELS; MEIRA, 2010).

\section{Nomes portugueses adaptados ao sistema fonológico da LG}

Os nomes emprestados do Português, ao entrarem no léxico da $L G$, sofreram adaptações fonológicas que os deixaram mais próximos das regras fonológicas da LG. Essas adaptações foram dividas em: (3.1) Adaptações segmentais; (3.2) Adaptações silábicas e (3.3) Adaptações acentuais.

4. O segmento $[\beta]$ foi considerado fonema por Rodrigues (1953). Todavia, essa análise é contestada por Cruz (2011, p. 86), que considera o $[\beta]$ como alofone, tendo em vista que a sua ocorrência é previsível. A análise de Cruz (2011), para o Tupinambá, é de que $[\beta]$ seria um alofone da nasal labial /m/. Cruz (2011) também difere de Monserrat (2008) por não considerar os glides como fonemas. 


\subsection{Adaptações segmentais}

Ao comparar os inventários fonológicos da LG e do Português do século XVIII, foram discutidas as diferenças entre os fonemas presentes em cada um desses sistemas. Tendo em vista tais diferenças, nomes emprestados do Português sofreram adaptações segmentais que os aproximaram mais do sistema consonantal da LG. Tais adaptações segmentais estão divididas da seguinte maneira: (3.1.1) rotacismo; (3.1.2) tendência à eliminação de fricativas labiais; (3.1.3) alofonia da fricativa palatal surda; (3.1.4) realização dos segmentos pré-nasalizados.

\subsubsection{Rotacismo}

O Português faz a distinção entre as líquidas / $/ /, / r /$, // e / / /. Em contraposição, a LG possui apenas uma líquida, o tepe $/ r /$. Quando uma dessas líquidas (/r, I, $\Lambda /$ ) aparece em um empréstimo do Português, ocorre, na LG, a adaptação fonológica que transforma esses fonemas em tepe /r/. Esse processo foi chamado por Câmara Jr. (1970) de rotacismo.

Nos exemplos de (1) a (16) abaixo, é possível observar a ocorrência do rotacismo com a aproximante lateral //. Sempre que o rotacismo ocorre com essa consoante em posição de coda, há também o aumento de uma sílaba na palavra emprestada em relação à palavra "original" do Português.

\begin{tabular}{|c|c|c|c|c|}
\hline & & (PB) /I/ & (LG & \\
\hline (1) & <alcatifa> & [al.ka.'t]i.fa] & <aracatifa> & [a.ra.ka.'t]i.fa] \\
\hline (2) & <alfavaca> & [al.fa.'va.ka] & <arfabaka> & [ar.fa.'ba.ka] ${ }^{5}$ \\
\hline （3） & <alicerce> & [ali.'scR.si] & <aricece> & [a.ri.'sc.si] \\
\hline (4) & $<$ altar $>$ & [al.'taR] & <aratara> & [a.ra.'ta.ra] \\
\hline （5） & $<$ almorreima> & [al.mo.'Rej. ma] & <aramoreyma> & [a.ra.mo.'rej. ma] \\
\hline (6) & $<$ anil $>$ & [a.'nil] & <andira> & [ã. ${ }^{\text {ndi.ra] }}$ \\
\hline (7) & <artemila> & [aR.te.'mi.la] & <aratemira> & [a.ra.te.'mi.ra] \\
\hline (8) & <balaio> & [ba.'la.ju] & <varaỹa> & [ßa.ra. .ja] \\
\hline (9) & <cebola> & [se.'bo.la] & <cebora> & [se.'bo.ra] \\
\hline (10) & $<$ funil $>$ & [fu.'nil] & $<$ funira $>$ & [fu.'ni.ra] [fu. 'ndi.ra] \\
\hline (11) & $<\operatorname{limão>}$ & [li.'mãv] & <rimáo> & [ri.'mao] \\
\hline (12) & $<$ martelo $>$ & [maR.'tc.lu] & $<$ martéra $>$ & [maR.'te.ra] \\
\hline (13) & $<$ melancia $>$ & [me.lãn.'si.a] & $<$ merancia $>$ & [me.rãn.'si.a] \\
\hline (14) & $<$ mulato $>$ & [mu.'la.tu] & $<$ muratú $>$ & [mu.ra.'tu] \\
\hline (15) & $<$ panela $>$ & [pã.'nc.la] & <panéra> & [pa.'ne.ra] \\
\hline (16) & <peroleira > & [pe.ro.'lej.ra] & $<$ piroréra $>$ & [pi.ro.'re.ra] \\
\hline
\end{tabular}

É importante observar que o /// em posição de coda é realizado como um glide lábio-velarizado [w] na maioria das variedades do Português moderno. Por exemplo, a palavra /pa'pel/ é pronunciada como [pa.'pew]. Similarmente, /alfa'vaka/ é realizada como [aw.fa.'va.ke]. É claro que tão somente a

5. Preferencialmente o tepe /r/ ocorre na posição intervocálica na LG. No entanto, Monserrat (2003, p. 193) observa que esse segmento também aparece esporadicamente em posição de coda. 
grafia de <papel> não permite afirmar se o final dessa palavra, no século XVIII, estava sendo realizado como [l] ou como [w], todavia, se a pronúncia fosse [pa.'pew], não haveria necessidade de adaptação por parte dos falantes de LG, uma vez que essa língua permite o ditongo [عw] em final de palavra, a exemplo da expressão /aiemo'meu/, provavelmente realizada como [a.je.mo.'mew], que significa 'eu me confesso', conforme pontua Monserrat (2003, p. 190). No entanto, o que acontece, na LG, é a adaptação de /pa'pel/ para [pa.'pe.re] e de /alfa'vaka/ para [ar.fa.'ba.ka] ${ }^{6}$, por exemplo. Nesse sentido, as adaptações feitas pelos falantes de LG sugerem, então, que falantes de Português do século XVIII ainda pronunciavam o /l/ como [l] em posição de coda.

Por sua vez, nos exemplos de (17) a (20) a seguir, o processo de rotacismo ocorre com a vibrante alveolar $/ \mathrm{r} /$.

\section{$(\mathrm{PB}) / \mathrm{r} /$}

(17)

(19)

(20)
$>$

$<$ baréra>

$<$ barete>

$<$ marica $>$

<pereirú>
(LG) /r/

[ba.'re.ra]

[ba.'re.ti]

[ma.'ri.ka]

[pe.rej.'ru]

No que concerne à aproximante lateral palatal $/ \Lambda /$, foram observados dois processos de adaptação fonológica: o rotacismo, exemplificado em (21), e a ditongação, exemplificado em (22).
(21) <borbulha>
(PB)/N/
$>$
(LG) / $/ \mathrm{r}$
[boR.'bu.Aa]
<bubura>
[bu.'bu.ra]
(PB)/N/
(22) <navalha>
[na.'va.রa]
$>$
<navaja>
(LG) [Vj]
[na.'va.ja]

No caso do exemplo (22), no lugar do rotacismo, ocorre uma ditongação. A ditongação é um processo fonético,causado por necessidades eufônicas no qual ocorre a troca da aproximante palatal/N/ para o glide, formando, deste modo, um ditongo. Esse tipo de processo é comum em alguns dialetos do Português europeu (especialmente no sul), além de ser uma propriedade comum de línguas cujo ancestral é o Português europeu, como o Português brasileiro e os crioulos de Sri-Lanka e Cabo Verde (cf. VIARO, 2005, p. 91). Pode-se, desta forma, levantar uma hipótese para a interpretação do exemplo (22) de que essa palavra foi pronunciada pelos colonizadores já como [na.'va.ja] e não sofreu nem um tipo de adaptação por parte dos falantes de LG. A ausência de exemplos de adaptação de / $/$ / no corpus, no entanto, não permite fazer nenhuma avaliação em termos de frequência dos dois tipos de adaptação (rotacismo ou ditongação), mas permite apenas indicar que os dois processos estavam presentes.

Além de ocorrer com as aproximantes, o rotacismo também foi encontrado como estratégia para adaptação fonológica da oclusiva coronal vozeada /d/. Os exemplos de (23) a (27) ilustram a mudança de /d/para /r/.

6. Convém ressaltar que o rotacismo da aproximante lateral /// em posição de coda também ocorre no Português brasileiro atual em determinados dialetos (cf. PINHO; MARGOTTI, 2010). 
No exemplo (27), é interessante pontuar, ainda, que, primeiramente, pode ter ocorrido o processo de adaptação silábica para transformar a sílaba CVC em duas sílabas CV (soldado > soladado), como ocorre em outros exemplos discutidos em 3.2. Com o rotacismo, a palavra seria adaptada para <sorararo> e sofreria o processo de haplologia, isto é, haveria a queda de uma sílaba semelhante, o que resultaria na palavra <soraro>. A troca do [o] final pelo [a] é rapidamente apresentada em também em 3.2.

\begin{tabular}{|c|c|c|c|c|c|}
\hline \multirow[b]{2}{*}{ (23) } & \multirow[b]{2}{*}{ <almofada> } & \multirow{2}{*}{$\begin{array}{l}(\mathrm{PB}) / \mathrm{d} / \\
{[\mathrm{al} . \mathrm{mo} . \mathrm{fa} . \mathrm{da}]}\end{array}$} & \multirow[t]{2}{*}{$>$} & \multicolumn{2}{|c|}{ (LG) / / / } \\
\hline & & & & <aramopara> & [a.ra.mo.'pa.ra] \\
\hline (24) & <camarada> & [ka.ma.'ra.da] & & <camarara> & [ka.ma.'ra.ra] \\
\hline (25) & <lâmpada> & ['lãm.pa.da] & & <arampara> & [a.rãm.'pa.ra] \\
\hline (26) & <sábado> & ['sa.ba.du] & & <sabarú> & [sa. ßa.'ru] \\
\hline (27) & <soldado> & [sol.'da.du] & & <sorara> & [so.'ra.ra] \\
\hline
\end{tabular}

Ao olhar para os tipos de rotacismos encontrados nos empréstimos da LG, pode-se afirmar que os traços [CORONAL] [+VOZ] são os traços fonológicos que fazem com que um segmento seja adaptado a um tepe.

\subsubsection{Tendência à eliminação de fricativas labiais}

O Português combina os traços [ \pm contínuo], [ \pm voz] e os lugares de articulação [LABIAL] e [CORONAL], além de [ \pm anterior], para criar a série de fricativas /f v s z $\int 3 /$. Diferentemente, a LG tem, em seu inventário fonológico, apenas a fricativa alveolar surda /s/ e a fricativa palatal surda / //, caracterizadas como [+ contínuo], traço que na LG aparece apenas para a coronal.

Tendo isso em vista, a fricativa labial do Português /f/ é adaptada para a LG como [- contínuo]. Os exemplos dessa adaptação serão listados no quadro 2.

Quadro 2: Adaptação da fricativa labial /f/

(PB) /f/ [+contínua, - vozeada] > (LG) /p/ [-contínua, - vozeada]

$\begin{array}{llll}<\text { alfinete } & \text { [al.fi.'ne.tfi] } & \text { <arapineta> } & \text { [a.ra.pi.'ne.ta] } \\ <\text { <almofada }> & \text { [al.mo.'fa.da] } & \text { <aramopara> } & \text { [a.ra.mo.'pa.ra] } \\ <\text { ferreiro } & \text { [fe.'xej.ro] } & \text { <pereirú } & \text { [pe.rej.'ru] } \\ <\text { fita }> & \text { ['fi.ta] } & <\text { pita }> & \text { [pi.'ta] }\end{array}$

No levantamento de dados, também foram encontrados dois vocábulos que possuem o fonema /f/, mas que não sofreram adaptação ao serem inseridos na LG. Visto isso, sabe-se que uma comunidade bilíngue tem a possibilidade de acessar o inventário fonológico das duas línguas que são faladas para atingir um determinado objetivo comunicativo. Dessa forma, o fato de a LG não adaptar uma palavra cuja a fricativa labial surda /f/ aparece pode ser um indício do avanço do processo de bilinguismo existente atualmente.

PB LG
(28) <alcatifa>
[al.ka.'t $t$ i.fa]
$<$ aracatifa>
[ara.ka.'t ti.fa]
(29) <funil>
[fu. 'nil]
$<$ funira>
[fu.'ni.ra] [fu. 'ndi.ra] 
Outro tipo de mudança que ocorre entre os empréstimos é a adaptação de /v/ para [b]. Essa adaptação poderia levar a crer que há, também, uma tendência à eliminação de uma fricativa semelhante à adaptação de /f/ para /p/. Contudo, nesse caso específico e levando em conta que a LG sequer possui o fonema oclusivo labial /b/ em seu inventário fonológico, uma outra hipótese pode ser levantada.

Sabe-se que a LG do século XVIII possuía um [ $\beta$ ] alofônico, que ocorria de acordo com a seguinte regra, conforme Cruz (2011):

$$
/ \mathrm{m} / \quad \rightarrow \quad[\beta] / \#_{-} ; V_{-} V
$$

No registro dos empréstimos que possuíam os segmentos [v] ou [b], o que pode ter acontecido é que esses vocábulos ora foram registrados com o grafema $\langle\mathrm{v}\rangle$, ora com o grafema $\langle\mathrm{b}\rangle$ nos documentos da LG, tendo em vista a proximidade dos dois sons com o fone [ $\beta]$. Essa alternância gráfica pode ser observada na variedade de formas de grafar os fonemas / $/$ e /b/ do Português nas palavras adaptadas à LG. Assim, o fonema /v/ do Português foi registrado graficamente ora como $\langle b\rangle$, como mostra o exemplo (30), ora como $\langle\mathrm{v}\rangle$, como mostra o exemplo (31). Por sua vez, o fonema /b/ do Português também foi registrado como o grafema <v> no empréstimo em (32).

Não há no corpus, no entanto, dados em que o fonema /b/ do Português seja representado como $\langle b\rangle$. Deve-se ainda atentar que o fonema /b/ do Português também foi muitas vezes interpretado como pré-nasalizada, tópico que será discutido na seção 3.1.4.

(PB)

(30) <cavalo>

(31) <chave>

(32) <balaio> [ka.va.'lu]

[ja. 'vi]

[ba.'laju]

LG

\begin{tabular}{|c|c|}
\hline <cabarú> & [ka.ßa.'ru] \\
\hline <xaví> & [ $\left[\mathrm{a}^{\prime} \cdot \mathbf{\beta i}\right]$ \\
\hline$<$ varaỹa > & [ßa. 'ra.ja] \\
\hline
\end{tabular}

\subsubsection{Alofonia da fricativa palatal surda}

Na Tupinambá, o fonema /s/ era realizado como o alofone [f] sempre que precedido ou seguido pela vogal /i/ (MONSERRAT, 2003). Essa regra pode ser descrita como a assimilação do traço [- anterior] da vogal/i/. As palavras em (33), (34) e (35) exemplificam essa alofonia.

$\begin{array}{lllll}(33) & \text { <japixá> } & \text { /iapi'sa / } & \text { [ja.pi.'Ja] } & \text { 'machucar' } \\ (34) & \text { <çapixára> } & \text { /sapi'sara/ } & \text { [sa.pi.'Ja.ra] } & \text { 'próximo' } \\ (35) & \text { <japuruxitá> } & \text { /iapurusi'ta/ } & \text { [ja.pu.ru.ji.'ta] } & \text { 'concha em espiral' }\end{array}$

Monserrat (2003, p. 193) afirma que, na LG do século XVIII, a fricativa palatal surda perdeu o seu caráter alofônico e passou a contrastar fonologicamente com /s/. Todavia, pode-se perceber que a regra fonológica de assimilação do traço [- anterior] ainda foi aplicada a dois empréstimos do Português ilustrado em (36) e (37) a seguir:
(PB)/s/
(36) <camisa>
[ka.'mi.za]
$>$
LG [S]
(37) <seringa>
[si.'rî.ga]
<camixá>
[ka.mi.'Sa]
$<$ xeringa $>$
$\left[\int \mathrm{i} .{ }^{\prime}\right.$ rî. $\left.{ }^{\mathrm{n}} \mathrm{ga}\right]$ 
Para a adaptação de /ka.' mi.za/, falantes de LG selecionam o traço [+ contínuo] do /z/, mas não o traço [+ voz]. Consequentemente, /z/ é interpretado como /s/. Depois disso, a regra de assimilação do traço [- anterior] é aplicada, formando [ka.mi.' Ja].

Em outros empréstimos, o fonema do Português / / é mantido como []] na LG, mesmo em um contexto no qual se esperaria /s/, como pode ser visto nos exemplos (38) e (39). Uma hipótese é que, por meio do contato com o Português, a LG tenha adquirido um novo contraste fonológico: /s/ em oposição a / //. Essa distinção, no entanto, é neutralizada quando o fonema /s/aparece precedido ou seguido vogal/i/, como foi visto nos exemplos (36) e (37).

\begin{tabular}{|c|c|c|c|c|}
\hline \multirow[b]{2}{*}{ (38) } & \multirow{2}{*}{\multicolumn{2}{|c|}{$\begin{array}{c}\text { PB } \\
\text { ['Sa.vi] }\end{array}$}} & \multicolumn{2}{|c|}{ LG } \\
\hline & & & <xaví> & [ \\
\hline (39) & <chocar> & [ $[0 . ' k a r]$ & <xóca> & ['Jj.ka] \\
\hline
\end{tabular}

É possível perceber que, no que diz respeito às fricativas palatais, as estratégias utilizadas para lidar com a fricativa palatal surda e sonora são diferentes. Enquanto a fricativa palatal surda / / é mantida nos vocábulos emprestados do Português, a fricativa palatal vozeada /3/ parece ter sido adaptada como glide [j], conforme mostrado nos exemplos (40) e (41).

É preciso deixar claro, no entanto, que o sistema ortográfico usado na documentação da LG não traz evidências claras sobre a pronúncia das palavras <janéra> e <jandára>. Sabe-se que o grafema <j> corresponde, na pronúncia do Português, à fricativa palatal sonora /3/, ao passo que, nos documentos produzidos por missionários, esse grafema, de acordo com Anchieta (1595, p. 5V), corresponde ao som do glide [j]. Portanto, aparentemente $<j>$ é pronunciado como um glide [jã. 'nda.ra], e não como uma fricativa palatal sonora [3ã. 'nda.ra], uma vez que /3/ não aparece no sistema fonológico da LG, conforme a análise de Monserrat (2003).

\section{PB LG}

\begin{tabular}{|c|c|c|}
\hline$<$ janela> & [3a.'ne.la] & <janéra> \\
\hline$<$ jantar> & [3ãn.'tar] & $<$ jandara $>$ \\
\hline
\end{tabular}

\subsubsection{Realização dos segmentos pré-nasalizados}

Conforme mencionado na seção 2, a LG não possui a tripla oposição entre a série de obstruintes surdas $/ p, t, k /$, obstruintes sonoras / $b, d, g /$ e as nasais / $m, n, n /$. Em vez disso, existe nessa língua o contraste entre obstruintes surdas $/ p, t, k /$ e uma série de nasais $/ m, n, \eta \mathrm{l} /$. As nasais poderiam ocorrer como nasais plenas $[m, n, \eta]$ ou como segmentos pré-nasalizados $\left[{ }^{m} b,{ }^{n} d,{ }^{n} g\right]$.

De acordo com Anchieta (1595), em posição inicial de palavra, jamais ocorriam as oclusivas [b] e [d] sozinhas ou a nasal dorsal [n]. Segundo Cruz (2011, p. 91), a nasal /m/ ocorre como nasal plena [m] ou como contorno [mb] após vogal nasal. Em meio de palavra, ainda segundo a autora, a nasal/n/ ocorre, em variação livre, como nasal plena [n] ou como contorno $\left[{ }^{\mathrm{n}} \mathrm{d}\right]$ em ataque silábico com núcleo oral.

Cruz (2011, p. 92 e 93) afirma ainda que, entre vogais orais e em posição de coda, depois de vogal oral, a nasal /m/ era implementada como fricativa labial [ $\beta$ ], grafada como $\langle b\rangle$, conforme ilustrado nos exemplos (42a) e (42b), e como [m] (ou como [mb]) depois de vogal nasal, conforme ilustrado nos exemplos (43a) e (43b) abaixo. 
(42a)

\#_V

<jukábo>

[ju.'ka.ßo]

'matar-gerúndio'

(42b)

$V_{\text {__\# }}$

<çoríb>

[so.'riß]

'alegria' (43a)

$\tilde{V}_{-}$V

< nupãmo>

[nu.'pã.mo]

'bater-gerúndio'

(43b)

$\tilde{v}_{-} \#$

<sém>

[sẽm]

'sair'

Cruz (2011, p. 92 e 93).

Uma vez que pré-nasalizadas não existiam nas línguas europeias, sua interpretação e, consequentemente, sua grafia tornaram-se um problema para os missionários que elaboraram a documentação sob análise. Embora existam instâncias em que os contornos foram grafados como $<m b\rangle_{\text {, }}<$ nd $>$ e $<$ ng $>$, não houve consistência na grafia.

Von Martius (1969 [1863]:29), durante a edição de documentos da LG do século XVIII, explicou a pronúncia de $<\mathrm{mb}>$ e indicou que a maneira como os vocábulos foram grafados nos dicionários do século XVIII não permite vislumbrar a complexidade desses segmentos:

\section{Mb, mit geschlossenem Munde, hört man oft, weil das Wort mbae, Sache, in vielen Zusammensetzungen erscheint. Auch bei zahlreichen andern Worten bemerkt man einen ähnlichen Zusammenschluss der Lippen, ohne dass jedoch diesem Laute in der Schreibung Rechnung getragen würde. \\ [Mb, produzido com a boca fechada, pode ser muito ouvido, porque a palavra mbae, "coisa", é usada em muitos compostos. Pode-se também observar um fechamento similar dos lábios em numerosas outras palavras, embora esse som não seja explicado na ortografia] (Von MARTIUS, 1969)[1863], p. 29, apud Cruz, 2005).}

Na medida em que as pré-nasalizadas obstruintes não foram explicadas na ortografia utilizada no dicionário, a investigação desse fenômeno tornou-se um quebra-cabeças. Em posição inicial de palavras, o fonema Português /b/ é representado em LG pelo grafema <m>. Como, na LG, a nasal /m/ ocorre como [ ${ }^{\mathrm{m} b}$ ] quando seguida por uma vogal oral, é possível que, nos empréstimos, o grafema $<\mathrm{m}>$ tenha sido utilizado para representar a pré-nasalizada obstruinte [mb] de início de palavra. Essa análise é coerente com a observação de que, em outras línguas indígenas da Amazônia que não têm a oposição entre obstruintes oral e nasal, a pré-nasalização é utilizada para tornar mais fácil a produção de uma obstruinte vozeada (WETZELS, 1995). Nos exemplos em (44), (45) e (46), a adaptação dos empréstimos em Português para a LG com o <m> são provavelmente pronunciados como [mb].

\section{PB}

(44) <barriga>

(45) <bexiga>

(46) <tambor> [ba.'hi.ga]

[be.' 'ji.ga]

[tãm.'boR]
LG

\begin{tabular}{|c|c|}
\hline <marĩca> & *[mba.' 'rî.ka] \\
\hline <mexîca> & * [mbe.' $\left.\int i . k a\right]$ \\
\hline <tambóra> & *[tã. 'mbo.ra] \\
\hline
\end{tabular}

Infelizmente, o dicionário do século XVIII não registrou nenhum nome em Português com obstruintes coronal e dorsal vozeadas / $/$ / e $/ \mathrm{g} /$ em início de palavra. No entanto, foram encontrados três empréstimos em que esses segmentos aparecem no meio de palavra, conforme mostrado em (47), (48) e (49). De acordo com Monserrat (2003, p. 188), diante de vogal oral acentuada, ocorrem os segmentos pré-nasalizados. 
PB

$\begin{array}{lll}(47) & <\text { jantar } & \text { [3ãn.'tah] } \\ (48) & <\text { quintal } & \text { [Ǩin.'tal] } \\ (49) & <\text { seringa }> & \text { [si.'rî̀.ga] }\end{array}$
LG

\begin{tabular}{|c|c|}
\hline <jandára> & *[ja. 'nda.ra] \\
\hline <kendara> & *[ke. ${ }^{\prime n}$ da.ra] \\
\hline <xeringa> & $*\left[\int i .{ }^{\prime} r r_{1}{ }^{n} \mathrm{ga}\right]$ \\
\hline
\end{tabular}

\subsection{Estrutura silábica}

As sílabas com consoantes em posição de coda (CVC, VC) e com ramificação do ataque silábico (CCV), presentes no Português, são desafios para os falantes de LG, tanto no que se refere à sua percepção quanto à sua produção. Para a solução dessas estruturas silábicas estranhas à LG, foram observadas três estratégias realizadas com a finalidade de adaptar sílabas CVC, VC e CCV: a epêntese de vogais, o apagamento de vogais e a metátese.

O primeiro processo discutido é o de epêntese. Nesse processo, há a inserção de uma vogal com a finalidade de adaptar uma sílaba com coda ocupada por consoante ou com ataque ramificado em duas sílabas CV. Em meio de palavra, é possível perceber, por meio dos exemplos (50) a (54) a seguir, que a vogal epentética não é uma vogal aleatória, mas a cópia da vogal que ocorre como núcleo da sílaba que sofrerá a adaptação.

(PB) VC, CVC, CCV

(50) <almoçar>

(51) <altar>

(52) <carpinteiro>

(53) <prato $>$

(54) <torto $>$ [al.mo.'sah]

[al.'tah]

[kah.pĩn.'tej.ro]

['pra.tu]

['toh. to]

$\begin{array}{ll}> & \text { (LG) CV.CV } \\ \text { <aramoçára> } & \text { [a.ra.mo.'sa.ra] } \\ \begin{array}{ll}\text { <aratara> } \\ \text { <carapina }>\end{array} & \text { [a.ra.'ta.ra] } \\ \text { <paratú> } & \text { [ka.ra.'pi.na] } \\ \text { <toroto }> & \text { [to. ro.'tu] }\end{array}$

Por sua vez, em final de palavra, pode-se perceber, nos exemplos (55) a (59), que a vogal epentética é, quase sempre, a vogal /a/, e não a cópia de outra vogal. Desse modo, é possível interpretar essa vogal como o morfema $\{$-a\} 'referenciante', utilizado para que um determinado vocábulo possa fazer referência a um ser ou a uma entidade (cf. QUEIXALÓS, 2006).

(PB) CVC

\begin{tabular}{|c|c|c|}
\hline （55） & <anel> & [a.'ngl] \\
\hline (56) & $<$ funil> & [fu.'nil] \\
\hline (57) & $<$ jantar> & [zãn.'tah] \\
\hline (58) & <papel> & [pa.'pel] \\
\hline (59) & $<$ quintal $>$ & [ǩnin.'tal] \\
\hline
\end{tabular}

\section{(LG) CV.Ca}

\begin{tabular}{|c|c|}
\hline <anéra> & [a.'nc.ra] \\
\hline$<$ funira $>$ & [fu.'ndi.ra] \\
\hline <jandára> & [ja. 'ndá.ra] \\
\hline <papéra> & [pa.'pe.ra] \\
\hline$<$ kendara > & [ke. ${ }^{\prime n}$ da.ra] \\
\hline
\end{tabular}

No exemplo (6o) a seguir, ocorre epêntese de uma vogal diferente de [a] na última sílaba da palavra. Nesse exemplo, antes da epêntese, ocorre o processo de harmonia vocálica. A harmonia vocálica é um tipo de assimilação, termo genérico usado para referir-se a qualquer processo em que um determinado som adquire características ou traços de sons que o rodeiam. De acordo com Trask (1996, p. 383), a harmonia vocálica é decorrente de um acordo em relação a um ou mais traços fonéticos. 
No caso do exemplo (60), a harmonia vocálica tem como gatilho a altura da vogal [u], que é uma vogal alta. Como a vogal [a] da última sílaba trata-se de uma vogal baixa, ela é adaptada para a vogal [i], que assimila o traço alto da vogal [u]. Por fim, o que parece ter havido é a epêntese da vogal [i], cópia do núcleo vocálico da sílaba adaptada. Este, no entanto, não parece ser um processo comum na língua, na medida em que só foi encontrado um exemplo do processo de harmonia vocálica seguido de epêntese.

PB

(6o) <açúcar> [a.'su.kah]
LG

<asukirí> [a.su.ki.'ri]

O segundo processo de adaptação silábica encontrado nos empréstimos é o apagamento de vogais. Neste processo, diferentemente da epêntese, observa-se o apagamento da consoante em coda, que impede a realização de uma sílaba CV. Os exemplos (61) e (62) ilustram essa adaptação.

\section{(PB) CVC}
(61) <castanha>
(62) <campo>
[kas.'tã.na]
['kãm.pu]

$>$

$\begin{array}{ll}<\text { catanha }> & \text { [ka.'tã.na] } \\ <\text { kapina } & {[\text { ka.'pi.na }]^{7}}\end{array}$

O terceiro e último processo observado para evitar estruturas silábicas estranhas à LG foi a metátese, processo linguístico que envolve uma inversão na ordem linear dos sons de um vocábulo sob determinadas condições. Segundo Hora, Telles e Monaretto (2007, p. 184), apesar de atualmente ser visto como um processo relacionado à escolaridade, o processo de metátese é um fenômeno antigo e persistente na Língua Portuguesa, vindo da passagem do Latim para o Português.

A metátese pode ser observada no exemplo (63) abaixo.

\section{(PB) VC}

(63) <espeto> [es.'pe.to] $\begin{array}{lr}> & (\mathrm{LG}) \mathrm{CV} \\ \text { <cepetú> } & {[\text { se.pe.'tu] }}\end{array}$

\subsection{Padrão acentual}

Como já foi citado na seção 2, a LG do século XVIII apresenta preferência um padrão acentual iâmbico, em que os pés métricos são formados da direita para a esquerda com proeminência à direita, característica presente na maioria das línguas da família Tupi-Guarani de acordo com Wetzels \& Meira (2010). Conforme Cruz (2011, p. 75-76), apesar de ter recebido bastante influência do Português brasileiro, o Nheengatu, variedade atualmente falada da LG, apresenta processos sincrônicos que indicam a preferência dessa língua por um padrão iâmbico.

No século XVIII, ocorrem dois processos que reestabelecem o padrão iâmbico preferido pela LG em empréstimos com padrão não-iâmbico vindos do Português: a mudança de acento e a epêntese seguida de mudança de acento.

Em empréstimos do Português em que o pé métrico final é formado por duas sílabas CV, ocorre

7. Apesar de os dicionaristas do século XVIII terem apontado 'kapina' como empréstimo de 'campo' em LG, é possível que, na verdade, 'kapina' empréstimo de 'campina'. 
simplesmente a mudança da posição do acento, que pode ser vista nos exemplos de (64) a (69), sem nenhum tipo de adaptação.

\begin{tabular}{|c|c|c|c|c|}
\hline & \multicolumn{2}{|c|}{ (PB) 'CVCV } & & (LG) CV'CV \\
\hline$(64)$ & <camisa> & [ka.'mi.za] & <camixá> & [ka.mi.'Sa] \\
\hline$(65)$ & <cavalo> & [ka.'va.lu] & <cabarú> & [ka.ba.'ru] \\
\hline (66) & <espeto> & [is.'pe.tu] & <cepetú> & [se.pe.'tu] \\
\hline$(67)$ & <chave> & ['Sa.vi] & <xaví & [ $[$ a.'vi] \\
\hline (68) & <sábado> & ['sa.ba.du] & <sabarú> & [sa.ba.'ru] \\
\hline (69) & $<$ fita $>$ & ['fi.ta] & <pitá> & [pi.'ta] \\
\hline
\end{tabular}

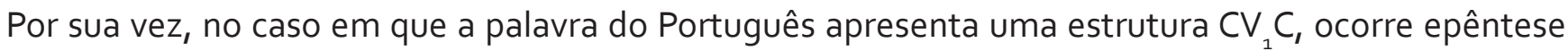
para formar sílabas $\mathrm{CV}_{1}{ }^{\prime} \mathrm{CV}_{2^{\prime}}$ com acento na última sílaba, como em (70), (71) e (72).

\begin{tabular}{|c|c|c|c|c|}
\hline \multirow[b]{2}{*}{ (70) } & \multicolumn{2}{|c|}{$(\mathrm{PB}) \mathrm{CV}_{1} \mathrm{C}$} & & $(L G) C V_{1}{ }^{\prime} C V_{2}$ \\
\hline & $<$ prato $>$ & ['pra.tu] & <paratú> & [pa.ra.'tu] \\
\hline (71) & <açúcar> & [a.'su.kar] & <asukirí> & [asu.ki.'ri] \\
\hline (72) & <cruz> & ['krus] & <curusá> & [ku.ru.'sa] \\
\hline
\end{tabular}

\section{Empréstimos verbais do Português na LG}

Foram encontrados apenas dez verbos emprestados do Português para a LG na documentação de análise. No quadro 3, podem ser vistos verbos emprestados que não sofreram nem um tipo aparente de adaptação fonológica; mas, ao contrário, que foram registrados de acordo com o sistema de escrita do Português. Nesse caso, nos vocábulos apresentados no quadro 3, poderão ser percebidas as violações dos verbos da LG ao que diz respeito ao inventário fonológico apresentado por Monserrat (2003) e ao que diz respeito à estrutura silábica da língua nativa.

Quadro 3: Verbos do Português adaptados para a LG e sua violações fonológicas

\begin{tabular}{|l|l|l|}
\hline Português & LG & Violações fonológicas na LG \\
\hline servir & $<$ servir $>$ & $\begin{array}{l}\text { *Coda R na posição medial; } \\
\text { *Fricativa labial [v]; }\end{array}$ \\
\hline valer & $<$ valer $>$ & $\begin{array}{l}\text { *Fricativa labial }[\mathrm{v}] ; \\
\text { *Lateral }[\mathrm{l}] ;\end{array}$ \\
\hline vender & $<$ vender $>$ & *Fricativa labial $[\mathrm{v}] ;$ \\
\hline se gabar & $<$ jegavar $>^{8}$ & *Fricativa labial $[\mathrm{v}] ;$ \\
\hline dever & $<$ dever & $\begin{array}{l}\text { *Obstruinte sonora }[\mathrm{d}] ; \\
\text { *Fricativa labial }[\mathrm{v}] ;\end{array}$ \\
\hline
\end{tabular}

8. Neste exemplo, o verbo gabar, adaptado, em LG, para gavar, recebeu o prefixo reflexico \{je-\}. Trata-se de um morfema de ajuste de valência, que age diminuindo a valência de um predicado transitivo. Ao inserir esse prefixo a uma base, expressa-se a ideia de que o argumento único é interpretado como agente e como paciente ao mesmo tempo. Uma análise mais minuciosa desses casos, em que a morfologia da LG funciona em empréstimos do Português, poderá ser realizada e discutida em trabalhos posteriores. 


\begin{tabular}{|l|l|l} 
prometer & <prometer> & *Ataque ramificado $[\mathrm{pr}]$.
\end{tabular}

Os verbos servir, valer, vender, dever mantiveram, ao menos na grafia, a fricativa sonora [v], enquanto o verbo gabar adaptou-se a e jegavar. Conforme sugerido na seção 3.1.2, a ocorrência do som [v] pode ser explicada devido à existência da fricativa labial $[\beta]$, alofone de [m], que ocorria sempre entre vogais orais ou em contexto oral no início de palavra. Desse modo, tendo em vista a proximidade do som [ $\beta]$ com a fricativa labiodental [v], acredita-se que os fonemas do Português / $/ \mathrm{e} / \mathrm{b} /$, no caso específico do verbo e jegavar, mesmo inexistentes no inventário fonológico da LG, possam ter sido entendidos e até grafados como <v> nos empréstimos da LG.

O verbo valer também não teve a sua aproximante lateral /// sofrendo rotacismo, como aconteceu com vários outros empréstimos nominais discutidos na seção 3.1.1. Outro exemplo a ser citado é o do verbo prometer, que não sofreu adaptação para evitar o ataque da sílaba ramificado, adaptação esperada conforme os empréstimos discutidos na seção 3.2. Por fim, nenhum verbo do quadro 3 recebeu epêntese de vogal para evitar a posição de coda ocupada por uma consoante na sílaba final.

Por outro lado, nos exemplos (73) e (74) a seguir, é possível observar dois verbos emprestados do Português que apresentam adaptações fonológicas, como é o caso do verbo almoçar, que sofre rotacismo na aproximante lateral /l/ e que recebe vogal epentética para evitar a posição de coda ocupada. Nesses exemplos, é provável que esses verbos tenham sido emprestados como nomes para a $L G$, isso tendo em vista que todos os outros verbos levantados não sofreram adaptações fonológicas aparentes.

PB
(73) <almoçar>
(74) <jantar>

LG

$\begin{array}{ll}<\text { aramoçára } & \text { [a.ra.mu.'sa.ra] } \\ <\text { jandára> } & \text { [ja. 'ndára] }\end{array}$

\section{Considerações Finais}

Neste trabalho, foram examinados os empréstimos do Português para a LG levantados a partir da Gramática da Língua Geral do Brasil com hum Diccionário dos vocabulários mais uzuaes para a intelligencia da dita Língua, do Dicionario da lingua geral do Brasil que se falla em todas as villas, lugares e aldeas deste vastissimo Estado e do Dicionário da Língua Brasílica. Esses documentos foram produzidos por missionários católicos no século XVIII.

O levantamento de dados permitiu observar que o número de nomes portugueses emprestados para a LG é superior ao número de verbos. Essa diferença numérica é coerente com a hierarquia de capacidade de empréstimo observado por Muysken (1981) e Matras (2009), os quais sugerem que nomes são mais facilmente emprestados que qualquer outra classe de palavras.

Os nomes emprestados sofreram adaptações com o objetivo de não violar o sistema fonológico da LG, enquanto a maioria dos verbos entrou na língua sem qualquer adaptação fonológica aparente. Uma possível explicação para isso é que poderia haver distintos mecanismos de adaptação para nomes e para verbos ou que esses verbos não estariam sendo usados pelos falantes em situações reais de fala.

Os mecanismos fonológicos de adaptação dividiram-se entre adaptação segmental, adaptação silábica 
e adaptação acentual. Sons que não fazem parte do inventário fonético da $L G$, como [z], [f], [v], [3], [r] e [l], passam por uma adaptação em LG. A exemplo, pode-se citar [l] e [d], que sofreram rotacismo, sendo adaptados para tepe [r], e [f], que se torna [p], perdendo o recurso [+ contínuo], mas mantendo o recurso [- voz]. A respeito da adaptação silábica, pode-se perceber que a LG realiza epêntese, apagamento e metátese para chegar a sílabas CV. Por sua vez, para a adaptação acentual, há mudança de acento em palavras cujo pé métrico final é formado por duas sílabas CV e epêntese, seguida de mudança de acento, em palavras que possuem sílabas CVC, para que o padrão iâmbico da LG seja recuperado.

\section{Referências}

Anchieta, J. de. Arte de gramática da língua mais usada na costa do Brasil. São Paulo: Editora Loyolla, 1990[1595].

ANÔNIMO. Gramatica da Lingua geral de Brazil com hum Diccionario dos vocabulos mais uzuaes para intelligencia da dita Lingua. Livraria de Coimbra: ms. 69, 1750. <Parte desse documento pode ser acessado em http://www.fflch.usp.br/dl/documental>

BORGES, M. V. Aspectos fonológicos e morfossintáticos do Avá-Canoeiro (Tupi-Guarani). 2006. Tese (Doutorado em Linguística) - Instituto de Estudos da Linguagem, Universidade Estadual de Campinas, Campinas, 2006.

CÂMARA, J. M. História e Estrutura da Língua Portuguesa. Rio de Janeiro: Editora Padrão, 1976.

CÂMARA, J. M. Introdução às línguas indígenas brasileiras. Rio de Janeiro: Livraria

Acadêmica, 1965.

CÂMARA, J. M. Estrutura da língua portuguesa. zed.. Petropólis, RJ: Vozes, 1970.

CLEMENTS, G. N. Representational economy in constraint-based phonology. In: HALL, T. A. (org.) Distinctive Feature Theory. Berlin: Mouton de Gruyter, 2001.

CRUZ, A. da. O Resgate da Língua Geral: modos de representação das unidades linguísticas da Língua Geral Brasílica e do Tupi Austral na obra de Martius (1794 - 1868). 2005. Dissertação (Mestrado em Linguística) - Faculdade de Filosofia, Letras e Ciências Humanas, Universidade de São Paulo, São Paulo, 2005.

CRUZ, A. da. O Estatuto de [s] e []] na Língua Geral Brasílica. IX Encontro dos Alunos de Pós-graduação em Linguística da USP (IX ENAPOL). São Paulo: Departamento de Linguística da Universidade de São Paulo, 2006. <Available at http://www.etnolinguistica.org/artigo:Cruz-2007>.

CRUZ, A. da. Fonologia e Gramática do Nheengatú: A língua geral falada pelos povos Baré, Warekena e Baniwa. Utrecht: LOT, 2011.

GRENAND, F.; EPAMINONDAS H. F. Pequeno Dicionário da Língua Geral. SEDUC / Núcleo de Recursos Tecnológicos, 1989.

MARTINS, M. F. Descrição e análise de aspectos da gramática do Guarani Mbyá. 2003. Tese (Doutorado em Linguística). - Instituto de Estudos da Linguagem, Universidade Estadual de Campinas, Campinas, 2003.

VON MARTIUS, K. F. P. Glossaria Linguarum Brasiliensium. Erlangen: Junge \& Sohn, 1969 [1863]. 
MATRAS, Y. Language Contact. Cambridge: Cambridge University Press, 2009.

MONSERRAT, R. M. F. O tupi do século XVIII (tupi-médio). In: BESSA FREIRE, J. R.; ROSA, M. C. (org.) Línguas Gerais: Política Linguística e Catequese na América do Sul no Período Colonial. Rio de Janeiro: Editora UERJ, 2003, p. 185-194.

MUYSKEN, P. 1981. Halfway between Quechua and Spanish: the case for relexification. In: A. Highfield and A. Valdman (org.) Historicity and variation in Creole studies, pp. 53-78. Arbor: Karoma.

PINHO, A. J. de; MARGOTTI, F. W. A variação da lateral pósvocálica /l/ no português do Brasil. Working Papers em Linguística, Florianópolis, v. 11, n. 2, p. 67-88, 2010.

RODRIGUES, A. D. Phonologie der Tupinambá-Sprache. 1958. Tese (Doutorado em Linguística). University of Hamburgo, 1958.

RODRIGUES, A. D. As Línguas Gerais Sul-Americanas. Papia: Revista Brasileira de Estudos Crioulos e Similares, São Paulo, v. 4, n. 2, p. 6-18, 1996.

SCHLEICHER, C. O. Comparative and Internal Reconstruction of Proto-Tupi-Guarani. University of Wisconsin-Madison, 1998.

SEKI, L. Gramática do Kamaiurá: Língua Tupi-Guarani do Alto do Xingu. Campinas, São Paulo: Editora da UNICAMP,Imprensa Oficial, 2000.

SILVA, R. V. M. e. O Português Arcaico: Fonologia. São Paulo: Contexto, 1991.

SOLANO, B. E. de J. Descrição gramatical da língua Araweté. 2009. Tese (Doutorado em Linguística) Instituto de Letras, Universidade de Brasília, Brasília, 2009.

STRADELLI, C. E. Vocabulário da língua geral português\&nheengatu e nheengatu-português, precedidos de um esboço de grammática nheengatu-poranduua. Rio de Janeiro. Revista do Instituto Histórico e Geográfico Brasileiro, v. 158, n. 104, p. 9-768, 1929.

TEYSSIER, P. 1990. História da Língua Portuguesa. [Tradução para o Português por Celso Cunha do original Histoire de la langue portugaise]. Lisboa: Livraria Sá da Costa Editora, 1990.

TRASK, R. L. A dictionary of phonetics and phonology. London: Routledge, 1996.

VIARO, M. E. Algumas considerações acerca do português falado quatrocentista e quinhentista. Papia: Revista de Crioulos de Base Ibérica, v. 15, n. 1, p. 80-101, 2005.

WETZELS, L. Estrutura Silábica e Contornos Nasais em Kaingáng. In WETZELS, L. (org.). Estudos Fonológicos das línguas indígenas brasileiras. Rio de Janeiro: Editora UFRJ, 1995, p. 265-296.

WETZELS, L. Primary Stress in Brazilian Portuguese and the Quantity Parameter. Journal of Portugues Linguistics, Special Issue on Prosody of the Iberian Languages, v. 5, n. 6, p. 9-58, 1977. 